\title{
Differenz
}

Revista internacional de estudios heideggerianos y sus derivas contemporáneas

AÑO 5, NÚMERO 4: JULIO DE 2018. e-ISSN 2386-4877 - DOI: 10.12795/Differenz.2018.i04.07

[pp. 111-117]

Recibido: $27 / 04 / 2018$

Aceptado: 05/06/2018

\section{RODRíGUEZ SUÁREZ, Luísa P. y GARCíA LANDA, José A. (2017). Corporalidad, Temporalidad, Afectividad. Perspectivas filosófico-antropológicas. Logos Verlag Berlin GmbH. Berlín.}

\section{Francisco Vázquez Manzano \\ Universidad de Granada}

El libro que nos ocupa supone no sólo un intento de reformulación de las tres nociones clave de las que trata el libro en el panorama filosófico contemporáneo sino además, y quizá lo más importante, un serio esfuerzo por entenderlas en sus mutuas implicaciones. Desde una redefinición de la corporalidad como la que se presenta en este libro, se muestra la necesidad de entender esa corporalidad en relación a las otras dos nociones como partes esenciales de esa nueva corporalidad reformulada.

En el capítulo "Corporalidad y existencia según Heidegger", Rodríguez Suárez analiza los Seminarios de Zollikon impartidos por Heidegger y en los que encontramos un tratamiento eminentemente filosófico del fenómeno de la corporalidad, tratamiento que, por otro lado, conecta el fenómeno del cuerpo con la propia existencia y, por tanto con los otros dos fenómenos de la afectividad y la temporalidad. En concreto, Heidegger no toma el cuerpo como un objeto a la manera en la que sí lo hace el reduccionismo de corte físiconatural. El cuerpo es visto por el alemán como "cuerpo experienciado" (Leibphänomen), destacando así su carácter hermenéutico y oponiéndolo a la visión tradicional que lo concibe como mero "cuerpo material" (Körper). 
También Felipe Johnson apunta a una nueva definición de lo corporal en relación directa con la existencia. Johnson además se apoya en la teoría hilemórfica de Aristóteles y en como la interpreta Heidegger. Desde esta recepción por parte del alemán, Johnson concluye que, en el caso concreto del ser humano, su eîdos -la psyché- es nôus o lo que es lo mismo, la unión entre un logos que pone al hombre en la tarea de abrir un horizonte comunitario mediante el habla y la praxis que lleva a cabo dicha tarea. La corporalidad humana, por su parte, se entiende como la concreción "material" de dicho eîdos, su efectivo ser-en-el-mundo comunitariamente abierto.

La relación constitutiva del Dasein con el mundo es, pues, corporal. De modo que el cuerpo, entendido como Leibphänomen sería un carácter fundamental de la existencia en tanto abierta al mundo circundante.

Esta visión del cuerpo nos lanza a una hermenéutica de la experiencia de la corporalidad. En esta dirección parece encaminarse Javier San Martín al llevar a cabo en su capítulo "Fenomenología y ciencia cognitiva", un análisis de la visión tripartita que Ortega y Gasset desarrolla a lo largo de su obra. Para Ortega, la vida presenta tres niveles: el nivel biográfico -nivel radical-, el nivel psicológico y el nivel biológico. El nivel biográfico es aquel nivel de lo vital que encuadra los diferentes proyectos vitales del individuo. En este sentido, parecen darse la mano esta visión de lo vital y la antes expuesta acerca de la corporalidad como Leibphänomen en tanto que apertura proyectiva al mundo.

Esta tripartición de lo vital lleva a San Martín a observar los prometedores avances de la fenomenología respecto a las ciencias cognitivas cuyo modelo neurofisiológico domina actualmente. La visión fenomenológica muestra como estos tres niveles existen legitimados en sí mismo y diferenciados pero presentando una interdependencia que no permite la reducción de uno a otro. Al mismo tiempo, esta visión tripartita de lo vital ofrece a la fenomenología una clara oportunidad para un uso práctico y orientador de la misma: el estudio de las psicopatologías desde una correcta articulación de los tres niveles expuestos.

Si bien, como vemos, es la corporalidad la que permite la apertura y constitución de un horizonte comunitario a través de los diferentes proyectos vitales constituidos en la relación con el mundo, según Johnson, para que esto ocurra es necesario que ese mundo "nos concierna": el mundo circundante tiene que ser visto por el existente como "concerniente" (sympherón), debe ser capaz de afectarlo. Por tanto la corporalidad en tanto que apertura al mundo es una apertura afectiva, lo que nos conecta con el segundo una de las otras dos nociones: la afectividad. 
La intencionalidad proyectivo-afectiva de la corporalidad es examinada por Francisco Rodríguez Valls en su capítulo "Afectividad e intencionalidad del cuerpo". Según Rodríguez Valls, la emotividad se identifica con dicha intencionalidad afectiva del cuerpo respecto al contexto en el que se encuentra. Ahora bien si la correlación entre estímulo-emociónrespuesta en el animal viene garantizada por su estructura instintiva, en el ser humano esta cadena se rompe, ya que ante el mismo estímulo el ser humano experimenta multitud de emociones diferentes. De esta particularidad se desprende un segundo aspecto específico de la emoción humana: ésta siempre va acompañada por capacidades cognoscitivas que no existen en el animal y que permiten una evaluación consciente de la evaluación inconsciente en la que radica la emoción. Así, la complejidad del organismo humano y su capacidad cognoscitiva son los dos aspectos específicos que Rodríguez Valls cree encontrar en la emotividad humana. Así como vemos, la afectividad de nuevo aparece como un rasgo -tanto humano como animal- que tiene la finalidad de una apertura de mundo.

Partiendo de esa corporalidad como apertura radical y la consideración de la misma como una apertura afectiva, varios artículos de esta obra analizan algunos fenómenos afectivos concretos. Es el caso de "Empatía y narrativa autobiográfica: Hermenéutica de la memoria" escrito por Beatriz Penas, quien a través de la lectura de Joseph Anton: $A$ memoir, novela de Salman Rushdie, nos muestra cómo la empatía entre lector y narrador conseguida por Rushdie mediante el uso de la narrativa autobiográfica puede convertirse en un medio de denuncia. Rushdie expone su caso (el de un condenado por la comunidad musulmana) como una violencia hacia su libertad de expresión. Al mismo tiempo, a través del uso de la empatía narrativa Rushdie consigue que todo lector de su obra se identifique con él y, así, conecte esa violencia hacia la libertad del autor y la denuncia acometida por éste, con su dimensión universal: Joseph Antón es un ejemplo de una dinámica general que hay que denunciar. La empatía narrativa es la que posibilita el éxito de tal denuncia.

Otro fenómeno afectivo concreto analizado en el libro es el amor. En sus respectivos capítulos ("Amor y perfección humana. El conocimiento interpersonal" y "Fenomenología del amor y la afectividad") Pedro Luis Blasco y Juan Velázquez se ocupan del amor como fenómeno derivado del carácter abierto de la existencia, el cual conduce al individuo a su realización completa. En el caso de Blasco, el autor considera que el amor está conectado con la idea de perfección. El ser humano viene al mundo en un estado completamente precario pero con unas potencialidades que sólo en el movimiento amoroso hacia lo "otro de sí" puede actualizar, alcanzando así su perfección constitutiva. Por su parte, Velázquez lleva a cabo una original fenomenología del amor. El amor sería un acto intencional que descubre en el objeto intencionado un valor más alto que aquellos que el objeto presenta 
objetivamente. Ese valor no lo crea el amor ex nihilo sino que parte del propio objeto pero sólo en tanto que amado. En la medida en que el amor "deja ser" al objeto en su valor más alto, Velázquez considera que dicho amor está completamente asociado a una verdadera comprensión del objeto.

El carácter afectivo y radicalmente abierto de la existencia humana queda patente en la noción butleriana de "performatividad" de la cual Elvira Burgos da cuenta en su capítulo "Amurallar afectos: Judith Butler y Wendy Brown". Se trata de una noción relativa principalmente al lenguaje. El lenguaje es visto como un decir que promueve inevitablemente una acción que ya se encuentra contenida en el propio lenguaje (algo semejante a lo señalado por Johnson en cuanto al nôus). Ahora bien, tradicionalmente, el lenguaje se ha entendido como originado a partir de un sujeto soberano que dictamina la dirección de la acción que el propio lenguaje implica. Butler, por el contrario, considera que el propio sujeto se constituye y nace en esa performatividad propia tanto del lenguaje como del sistema socio-cultural en el que se desenvuelve. El cambio de perspectiva implica la renuncia al sujeto como soberano de la performatividad ya que toda acción contenida en una significación es heterogénea y lanzada en múltiples direcciones, sin dirección previa establecida por el sujeto. Es la repetición de las mismas significaciones en una misma dirección la que constituye normas desde las cuales se pre-configura la dirección de la acción implícita en la significación. Cuando estas normas se rompen, los sujetos constituidos en esa performatividad pierden su solidez y se demuestran como lo que son: meras aperturas a toda una pleura de relaciones y posibilidades. Ante esta situación existen dos reacciones: una reacción "masculina" que busca la impenetrabilidad del sistema, esto es, la restitución de las murallas como las llama Brown que dotan a la performatividad de un carácter meramente activo y realizativo; y, por otro lado, una reacción "femenina" que incide en el carácter permeable y proteico del propio sistema normativo y que lo lanzan al ensayo de nuevas líneas de significación y acción en la que se prima la inter-afección, la pasividad ante una afección externa y la ausencia de reparo a una transformación motivada por esa afección. Sólo desde esta idea de performatividad, como una afectividad no supeditada a reglas sino, por el contrario, generadora de reglas sin una regla prexistente, puede entenderse según la autora, una verdadera propuesta feminista, algo que, en mi opinión, choca con el capítulo que examinamos a continuación.

En "La subjetividad en la temporalidad nómada de Rosi Braidotti", Aránzazu Hernández Piñero parte de las mismas premisas que Elvira Burgos: la existencia se concibe como pura apertura afectiva, siendo toda subjetividad y sistema socio-cultural resultado de esas relaciones afectivas. Braidotti, como nos cuenta Hernández Piñero, se encuentra muy influenciada por la obra de Deleuze y por lo que se ha dado en llamar el "giro espacial" 
que Deleuze acomete. Así, desde este autor, Braidotti considera que el sujeto es un sujeto "nómada": un sujeto localizado en una red de relaciones sociales y simbólicas. Ahora bien, dicha localización, no se entiende como una suma de diferencias (la diferencia sexual, la étnica, etc.) que conceda una identidad al sujeto por así decirlo negativa. Por el contrario, la localización se debe a la sincronización interna tanto de la propia red de relaciones sociales y simbólicas como de sus diferencias en una "unidad" que resulta internamente contradictoria. Este es el carácter espacial de la localización. Pero la localización también reviste una dimensión temporal que tiene que ver con la capacidad de la misma para persistir en su identidad pese a las múltiples relaciones diferenciales en las que se encuentra. Según Hernández Piñero, la persistencia de la subjetividad depende de la capacidad de expresar y aumentar la "propia potencia" que el sujeto encarna. El sujeto nómada en Braidotti se entiende, pues, desde su espacialidad (localización entendida como sincronización de una red diferencial) y su temporalidad (persistencia de esa localización). A su vez, desde esta noción de subjetividad nómada, Braidotti entenderá el papel del feminismo como una política de la localización de la subjetividad femenina. Ahora bien, en este punto Braidotti parece traicionar el principio fundamental de toda filosofía de la diferencia: el carácter múltiple y plural de toda potencia. Si entendemos el sujeto como potencia encarnada, esta potencia ha de entenderse no en su singularidad sino también desde una red de interrelaciones en las que una potencia se define por su relación con las demás. En definitiva, no podríamos hacer depender la persistencia de algo así como la "propia potencia" en la medida en que no existe tal cosa: toda potencia implica una red relacional de potencias y toda encarnación de este suelo, integra en sí esa contradicción, luego no hay un sí mismo que pueda persistir sino, a lo sumo, una determinada organización de la red intensiva que cada sujeto encarna. La persistencia, por tanto, tendría que ver con esa red y no con la localización singular. La subjetividad femenina aparece para Braidotti en una posición subordinada. Esto es innegable. Ahora bien, la manera en la que dicha subjetividad puede adquirir preponderancia, no es a través de un esfuerzo por su perdurabilidad y su aumento de potencia, ya que tal subjetividad depende de un entramado que la sobrepasa. Sólo desde una transformación de dicho entramado intensivo, se podría llevar a cabo una política feminista que, eso sí, implicara una transformación radical de la subjetividad femenina, algo que desde el planteamiento de Braidotti no puede realizarse.

Pese a lo dicho, Braidotti descubre un elemento esencial a la afectividad y la corporalidad humana: su dimensión temporal. Lazar Koprinarov, en su capítulo "El vestir o el cuerpo como nómada" se dirige hacia la consideración temporal de la corporalidad y la afectividad humana en base a una dimensión peculiar de las mismas: el vestir. El vestir, 
según Koprinarov ejemplifica perfectamente el "nomadismo" del propio cuerpo, esto es, la transformación y la permanencia del cuerpo en su identidad. Para Koprinarov, el vestir es una dimensión que aúna la afectividad y la corporalidad y a la vez pone a ambas en relación con el tiempo socio-cultural. Para mostrar esto, Koprinarov se detiene en el fenómeno de la moda. La moda tiende a cumplir dos exigencias paradójicas del individuo, a saber, una demanda de armonía social, por un lado, y el deseo de diferenciarse y desmarcarse del resto, por otro. Esto lo cumple en la medida en que la moda impone la necesidad de constante transformación. Sin embargo, al someterse a este cambio constante y el gusto por la diferencia, el individuo no hace sino lo que todos: seguir los patrones de la moda. De manera que la cohesión social se mantiene en la diferencia: todos se diferencian de todos y buscan hacerlo, y en esa medida, todos permanecen bajo los mismos patrones conductuales.

La dimensión temporal de la afectividad, por último, es también tratada por José Ángel García Landa en su capítulo "George Herbert Mead y la complejidad del tiempo humano". Los signos y la propia identidad personal, para García Landa, se hayan constituidos en un interaccionismos afectivo-simbólico al que el individuo humano se encuentra lanzado debido a su apertura afectiva radical. García Landa trata de analizar los apuntes realizados por Herbert Mead respecto a este punto. Para Mead, el presente es visto como el ámbito de ubicación de lo real. Mead combate la idea de que exista un tiempo más allá del tiempo, es decir, la concepción de un pasado y un futuro independientes del presente. El pasado, para Mead, es construido y seleccionado respecto a las acciones e interacciones que constituyen el presente, del mismo modo que el futuro se observa como las posibilidades de acción virtuales ofrecidas por el momento presente. Así pues, tanto el pasado como el futuro existe sólo en relación a fines interaccionales y comunicativos propios de la afectividad humana los cuales, por su parte, dotan de una "unidad en la diferencia" al yo personal, en un sentido semejante al que vimos en el capítulo anterior. El yo integraría todo lo emergente con aquello de lo cual emerge, esto es, el yo integraría el pasado con el futuro a través de su acción con el entorno. A su vez, el entorno es visto como el resultado de la interacción de los organismos que lo componen, interacción siempre tendente al futuro.

Tras este repaso necesariamente escueto por los distintos capítulos de este título, podemos concluir que nos encontramos ante un magnífico libro colectivo en el que cada una de las aportaciones, pese a su heterogeneidad, forman parte de un objetivo común: mostrar como corporalidad, temporalidad y afectividad se entrecruzan en la problemática de la propia identidad tanto social como personal del individuo. Esto abre posibilidades 
y, a su vez, demarca los límites para acometer la tarea de una antropología filosófica que tenga siempre en mente estas tres dimensiones inseparables y busque en su interacción la génesis de lo propiamente humano. 